УДК 665.939 .56

\title{
ТЕХНОЛОГИЯ УДАЛЕНИЯ СВОБОДНОГО ФОРМАЛЬДЕГИДА ИЗ КАРБАМИДОФОРМАЛЬДЕГИДНЫХ СМОЛ
}

\author{
Липин Константин Владимирович1, \\ lipinkost@mail.ru
}

\author{
Федосеев Сергей Владимирович1, \\ sergey.fedoseev88@gmail.com
}

\author{
Кизяев Денис Алексеевич², \\ denis.kizyaev@yandex.ru \\ 1 Чувашский государственный университет имени И.Н. Ульянова, \\ Россия, 428015, г. Чебоксары, пр. Московский, 15. \\ 2 ПАО «Химпром», \\ Россия, 429965, г. Новочебоксарск, ул. Промышленная, 101
}

\begin{abstract}
Актуальность исследования обусловлена высокой опасностью техногенной эмиссии формальдегида в окружающую среду. Основным антропогенным источником формальдегида является производство древесностружечных плит, в которых применяются карбамидофрормальдегидные смолы. В работе предлагается технология удаления свободного формальдегида из карбамидоформальдегидных смол, что повысит безопасность и экологичность продукции на их основе. Результаты работь позволят безопасно утилизировать и наиболее оптимально использовать имеющиеся георесурсы, тем самым решая одну из основных задач геоэкологии.

Целью данного исследования является разработка способа снижения токсичности карбамидофрормальдегидных смол за счет удаления свободного формальдегида.

объекты: карбамидоформальдегидные смолы, характеризующиеся возможностью эмиссии фрормальдегида.

Методы: моделирование оптимальных параметров процесса; лабораторные методы удаления формальдегида; лабораторные методы исследования физико-механических свойств модифицированной карбамидоформальдегидной смоль; моделирование необходимого оборудования; моделирование технологической схемы.

Результаты. Была разработана лабораторная установка для удаления формальдегида из карбамидоформальдегидных смол, и подобраны оптимальные условия проведения процесса: рекомендуемый интервал $\mathrm{pH}$ составляет 3,5...4,0, температуру рекомендуется поддерживать в интервале $20-40{ }^{\circ} \mathrm{C}$, количество гидросульфрита натрия должно составлять $1,5 . . .1,75$ от стехиометрического соотношения, процесс рекомендуется проводить при атмосфеерном давлении. На основе лабораторной установки разработана технологическая схема получения экологически безопасных карбамидофоормальдегидных смол, состоящая из двух стадий: приготовление реагента гидросульфита натрия и взаимодействие его с карбамидофоормальдегидной смолой. Было подобрано необходимое основное и вспомогательное оборудование. Для проведения процесса необходимо два реактора с рубашкой и мешалкой, три насоса-дозатора и бак для хранения соляной кислоты. В рамках данного исследования было проведено изучение фризико-механических свойств модифицированной карбамидоформальдегидной смолы. Полученные результаты несколько отклоняются от показателей исходной карбамидоформальдегидной смолы, но находятся 8 пределах допустимых норм.
\end{abstract}

\section{Ключевые слова:}

Формальдегид, карбамидоформальдегидные смолы, эмиссия формальдегида, удаление формальдегида, модифрикация карбамидоформальдегидной смолы.

\section{Введение}

Одной из основных задач геоэкологии является изучение проблемы безопасной утилизации георесурсов. В список наиболее опасных антропогенных загрязнителей окружаюшей среды входит формальдегид, образующийся при производстве и использовании древесностружечных плит. Утилизация свободного формальдегида путем перевода в менее токсичное соединение является актуальной проблемой геоэкологии.

Карбамидоформальдегидные (КФ) смолы являются основным связующим материалом для производства древесностружечных и древесных плит [1]. Их получают поликонденсацией карбамида и формальдегида. Кроме этого, КФ смолы применяют, как эмульсионные краски [2], конденсаторы в электрохимии $[3,4]$, для получения нанопорошков [5] и сорбен- та для удаления загрязнений из сточных вод [6]. В последние годы КФ смолы часто находят применение в агрохимии [7, 8].

Применение КФ смол ограничивает возможность эмиссии формальдегида во время использования. Формальдегид внесен в список канцерогенных веществ, обладает токсичностью, негативно воздействует на генетический материал, репродуктивные органы, дыхательные пути, глаза, кожный покров. На сегодняшний день разработаны классы токсичности клеевых композиций в зависимости от содержания свободного формальдегида, и разработка новых методов получения экологически безопасных КФ смол является актуальной задачей [9-22].

Целью данного исследования является разработка способа снижения токсичности КФ смол за счет удаления свободного формальдегида 


\section{Обсуждение результатов}

Наиболее часто для снижения концентрации свободного формальдегида в смоле меняют лишь соотношение карбамида с формальдегидом или порядок, величину и количество загрузок. Данные методы характеризуются изменением технологического процесса, технологических режимов и не позволяют модифицировать уже готовую КФ смолу непосредственно на предприятии, использующем ее для различных целей.

Нами предлагается способ модификации КФ смол с целью снижения концентрации свободного формальдегида в ее составе без изменения физикомеханических и химических параметров смолы и изделий на ее основе путем обработки гидросульфитом натрия.

При взаимодействии гидросульфита натрия и формальдегида протекает реакция образования гидроксиметансульфоната натрия:

$$
\mathrm{HCHO}+\mathrm{NaHSO}_{3} \rightarrow \mathrm{HOCH}_{2} \mathrm{SO}_{3} \mathrm{Na} \text {. }
$$

Таким образом, в ходе реакции вредный и канцерогенный формальдегид (2 класс опасности) переходит в гидроксиметансульфонат натрия (3 класс опасности) и понижается токсичность получаемой КФ смолы.

В ходе предварительных лабораторных экспериментов было обнаружено, что гидросульфит натрия полностью связывает свободный формальдегид КФ смолы. Концентрацию формальдегида определяли прямым потенциометрическим титрованием раствором гидроксиламина гидрохлорида.

Для достижения поставленной цели на следующем этапе работы было решено подобрать оптимальные условия для проведения процесса связывания свободного формальдегида из смолы, разработать технологическую схему, подобрать основное и вспомогательное оборудование.

Первоначально была поставлена задача подобрать оптимальные технологические параметры проектируемого процесса.

Стабильность протекания реакции взаимодействия свободного формальдегида и реагента гидросульфита натрия во многом зависит от $\mathrm{pH}$ среды, поскольку гидросульфит натрия имеет ограниченный интервал устойчивости. Изменение допустимого $\mathrm{pH}$ среды приводит к его разрушению: при снижении $\mathrm{pH}<3,5$ происходит распад гидросульфита натрия до $\mathrm{SO}_{2}$ $\mathrm{NaCl}$ и $\mathrm{H}_{2} \mathrm{O}$ (при подкислении соляной кислотой); при увеличении $\mathrm{pH}>4,0$ гидросульфит натрия переходит в форму сульфита натрия. Таким образом, установленный нами интервал рН составляет $3,5 \ldots 4,0$.

На процесс связывания формальдегида также будет оказывать влияние температура реакционной массы. Отверждение смолы происходит при повышении температуры до $100-130{ }^{\circ} \mathrm{C}$. Соответственно, структурные изменения в смоле начинаются при 80-90 ${ }^{\circ} \mathrm{C}$, поэтому достижение такой температуры нельзя допускать. При температурах ниже $+5{ }^{\circ} \mathrm{C}$ также происходят нежелательные структурные изменения, так как в состав смолы входят мочевина, формальдегид, поливинилацетат, вода. Таким образом, интервал температур 5-90 ${ }^{\circ} \mathrm{C}$ является наиболее благоприятным для такого вида взаимодействия. Были проведены исследования влияния на взаимодействие температур 30, $40,50,60,70$ и $80{ }^{\circ} \mathrm{C}$. Выявлено, что при значениях температур 60, 70 и $80{ }^{\circ} \mathrm{C}$ гидросульфит натрия разлагается с выделением $\mathrm{SO}_{2}$. При других исследованных значениях температуры было замечено незначительное увеличение скорости реакции, которое не оправдывается затратами энергоресурсов. Таким образом, рабочую температуру рекомендуется поддерживать в интервале $20-40{ }^{\circ} \mathrm{C}$.

$\mathrm{C}$ увеличением концентрации связующего реагента увеличивается полнота реакции связывания формальдегида. Концентрация свободного формальдегида в смоле постоянна и находится в пределе 0,15...0,9 \% мас. (по ГОСТу и ТУ), поэтому увеличение количества гидросульфита натрия больше чем в 2 раза превышающего стехиометрическое соотношение по реакции не приводит к заметному увеличению скорости процесса. Взаимодействие решили проводить при концентрациях гидросульфита натрия, превышающих стехиометрическое соотношение в $1,5 \ldots 1,75$ раз.

При исследовании влияния УФ-излучения на реакцию взаимодействия свободного формальдегида и гидросульфита натрия нами не было выявлено никаких изменений, ни в скорости реакции, ни в полноте ее протекания.

При снижении давления (менее 0,1 МПа) интенсифицируется процесс эмиссии свободного формальдегида из реакционной массы, благодаря чему связывание его с гидросульфитом не происходит вследствие большой скорости эмиссии. При повышении давления до 0,15 МПа нами не было замечено значительного увеличения скорости реакции, которое оправдывалось бы затратами энергоресурсов. Таким образом, данный процесс рекомендуется проводить при атмосферном давлении (0,1 МПа).

В итоге были выбраны оптимальные условия для проведения реакции связывания свободного формальдегида в КФ смолах гидросульфитом натрия:

1) рекомендуемый интервал $\mathrm{pH}$ составляет $3,5 . .4,0$;

2) рабочую температуру рекомендуется поддерживать в интервале $20-40{ }^{\circ} \mathrm{C}$;

3) количество гидросульфита натрия, необходимого для связывания свободного формальдегида, составляет $1,5 \ldots 1,75$ от стехиометрического соотношения;

4) рекомендуется проводить связывание свободного формальдегида при давлении 0,1 МПа.

Для проверки оптимальных условий проведения процесса была разработана и собрана лабораторная установка удаления формальдегида из КФ смол, которая представлена на рис. 1.

В емкость для приготовления раствора гидросульфита натрия $\mathrm{NaHSO}_{3}-2$, заливается вода и сульфит натрия в количествах, необходимых для получения $25 \%$-го раствора. Также из расходной емкости - 4 в емкость приготовления подается точное количество соляной кислоты $\mathrm{HCl}$, необходимое для протекания реакции, при этом ведется постоянное измерение $\mathrm{pH}$ 
при помощи рН-метра - 1. При помощи магнитной мешалки - 3 поддерживается скорость перемешивания раствора 200 об/мин и температура реакционной массы 20-40 ${ }^{\circ} \mathrm{C}$. Приготовленный раствор гидросульфита натрия при помощи крана-дозатора - 5 загружается в реактор удаления формальдегида - 6, куда заранее была загружена карбамидоформальдегид- ная смола и включен электродвигатель с мешалкой 8. В случае необходимости подкисления реакционной массы в ходе процесса из расходной емкости - 7 подается соляная кислота. Скорость перемешивания раствора соблюдаются и контролируются. Готовая модифицированная смола при помощи крана - 9 выгружается из реактора.

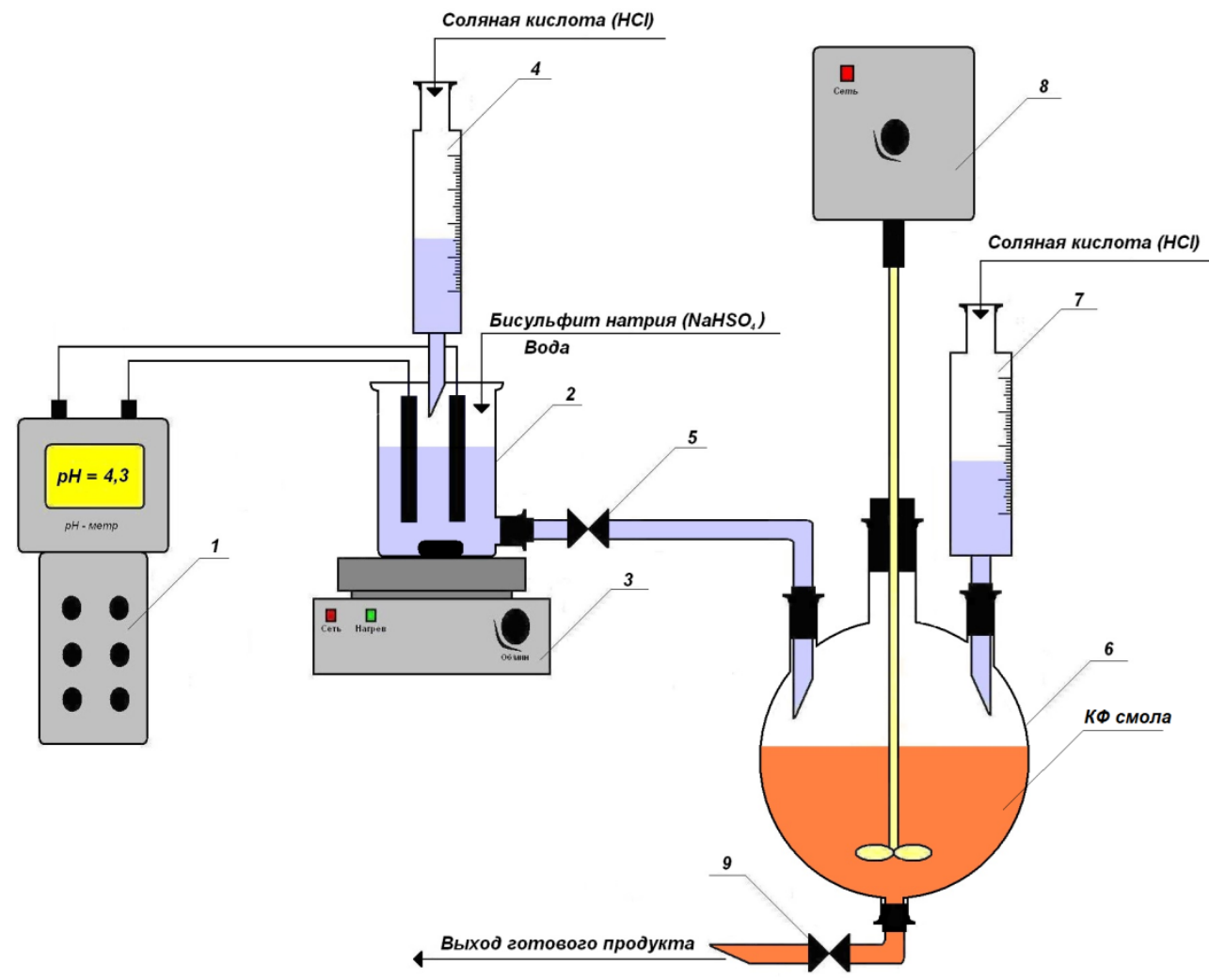

Рис. 1. Лабораторная установка удаления формальдегида из КФ смол: 1 - рН метр (pH-150 МИ); 2 - емкость для приготовления раствора гидросульфита натрия $\left(\mathrm{NaHSO}_{3}\right) ; 3$ - магнитная мешалка; 4 - расходная емкость соляной кислоты $(\mathrm{HCl}) ; 5$ - кран-дозатор подачи реактива в реактор; 6 - реактор для удаления формальдегида; 7 - расходная емкость соляной кислоты (HCl); 8 - электродвигатель с мешалкой; 9 - кран выхода готового продукта

Fig. 1. Laboratory installation for the removal of formaldehyde from UF resins: 1 - pH meter ( $p H-150 \mathrm{MI}) ; 2-$ container for preparing a solution of sodium hydrosulfite ( $\left.\mathrm{NaHSO}_{3}\right)$; 3 - magnetic stirrer; 4 - consumable capacity of hydrochloric acid $(\mathrm{HCl}) ; 5$ - metering valve for supplying the reagent to the reactor; 6 - reactor for formaldehyde removal; 7 - consumable capacity of hydrochloric acid $(\mathrm{HCl}) ; 8$-electric motor with a stirrer; 9 - product outlet tap

При проведении лабораторных экспериментов была подтверждена работоспособность разработанной методики.

Было проведено исследование физико-механических свойств модифицированной КФ смолы. Полученные результаты несколько отклоняются от результатов исследования исходной КФ смолы, но находятся в пределах допустимых норм. Результаты исследования свойств КФ смолы до и после связывания свободного формальдегида представлены в таблице.

На основе лабораторного метода было решено разработать технологическую схему удаления формальдегида из КФ смол.

Технологический процесс разделен на 2 стадии (рис. 2): 1 - приготовление реагента гидросульфита натрия; 2 - взаимодействие гидросульфита натрия с карбамидоформальдегидной смолой.
1 стадия. Приготовление концентрированного раствора гидросульфита натрия путем взаимодействия водного раствора сульфита натрия с соляной кислотой при строгом контроле за изменением $\mathrm{pH}$ реакционной смеси, осуществляется в реакторе - 1 с рубашкой для поддержания постоянной температуры и мешалкой для перемешивания.

Насыщенный водный раствор гидросульфита натрия, приготовленный непосредственно в реактоpe - 1 путем дозирования воды и сухого реагента, вводят в контакт при помощи насоса-дозатора - 2 концентрированной соляной кислотой из емкости хранения соляной кислоты - 3. Дозировка соляной кислоты останавливается до достижения суммарной концентрации восстановителей в конечном растворе в диапазоне $1,9 \ldots 2,5$ моль/кг, или 2,5...3,1 моль/л, таким образом, чтобы $\mathrm{pH}$ реакционной смеси по ходу 
процесса не оказывался менее 6, а в момент завершения был 3,5...4,5, после чего процесс прекращают, полученный раствор подают при помощи насоса - 5 на вторую стадию взаимодействия раствора гидросульфита натрия с КФ смолой.

2 стадия. В реактор - 6, снабженный рубашкой для поддержания постоянной температуры реакционной смеси и мешалкой, загружается КФ смола и включается перемешивание. В реактор при помощи насоса - 5 дозируется реагент - гидросульфит натрия, в количестве, необходимом для реакции. Внутри реактора постоянно контролируется температура и рН среды, при необходимости $\mathrm{pH}$ среды в реакторе подкисляется соляной кислотой из емкости - 3 при помощи насоса -4 .

По истечении времени реакции отбирается проба на анализ содержания свободного формальдегида в смеси, а также физико-механических свойств. При положительных результатах анализа перемешивание останавливается и с нижнего штуцера реактора выгружается готовый продукт - модифицированная КФ смола.
Таблица. Показатели физико-механических свойств КФ смолы до и после связывания свободного формальдегида

Table. Indicators of the physico-mechanical properties of $U F$ resin before and after binding of free formaldehyde

\begin{tabular}{|c|c|c|c|}
\hline \multirow[b]{2}{*}{ Свойства/Properties } & \multicolumn{3}{|c|}{ Значение/Value } \\
\hline & $\begin{array}{c}\text { До } \\
\text { Before }\end{array}$ & \begin{tabular}{|c|} 
После \\
After
\end{tabular} & $\begin{array}{l}\text { Норма } \\
\text { Norm }\end{array}$ \\
\hline $\begin{array}{l}\text { Условная вязкость при }(20,0 \pm 0,5)^{\circ} \mathrm{C}, \mathrm{c} \\
\text { Conditional viscosity at }(20,0 \pm 0,5)^{\circ} \mathrm{C}, \mathrm{s}\end{array}$ & 43 & 38 & $35-50$ \\
\hline $\begin{array}{l}\text { Время желатинизации при } 100^{\circ} \mathrm{C}, \mathrm{c} \\
\text { Gelation time at } 100^{\circ} \mathrm{C}, \mathrm{s}\end{array}$ & 57 & 45 & $40-65$ \\
\hline $\begin{array}{l}\text { Предел прочности при скалывании по } \\
\text { клеевому слою фанеры после выма- } \\
\text { чивания образцов в воде в течение } \\
24 \text { ч, МПа } \\
\text { Ultimate shear strength over the glue } \\
\text { layer of plywood after soaking the } \\
\text { samples in water for } 24 \mathrm{~h}, \mathrm{MPa}\end{array}$ & 1,5 & 1,5 & 1,5 \\
\hline $\begin{array}{l}\text { Плотность при } 20^{\circ} \mathrm{C}, \Gamma / \mathrm{cm}^{3} \\
\text { Density at } 20^{\circ} \mathrm{C}, \mathrm{g} / \mathrm{cm}^{3}\end{array}$ & 1,27 & 1,25 & $1,25 \ldots 1,28$ \\
\hline
\end{tabular}

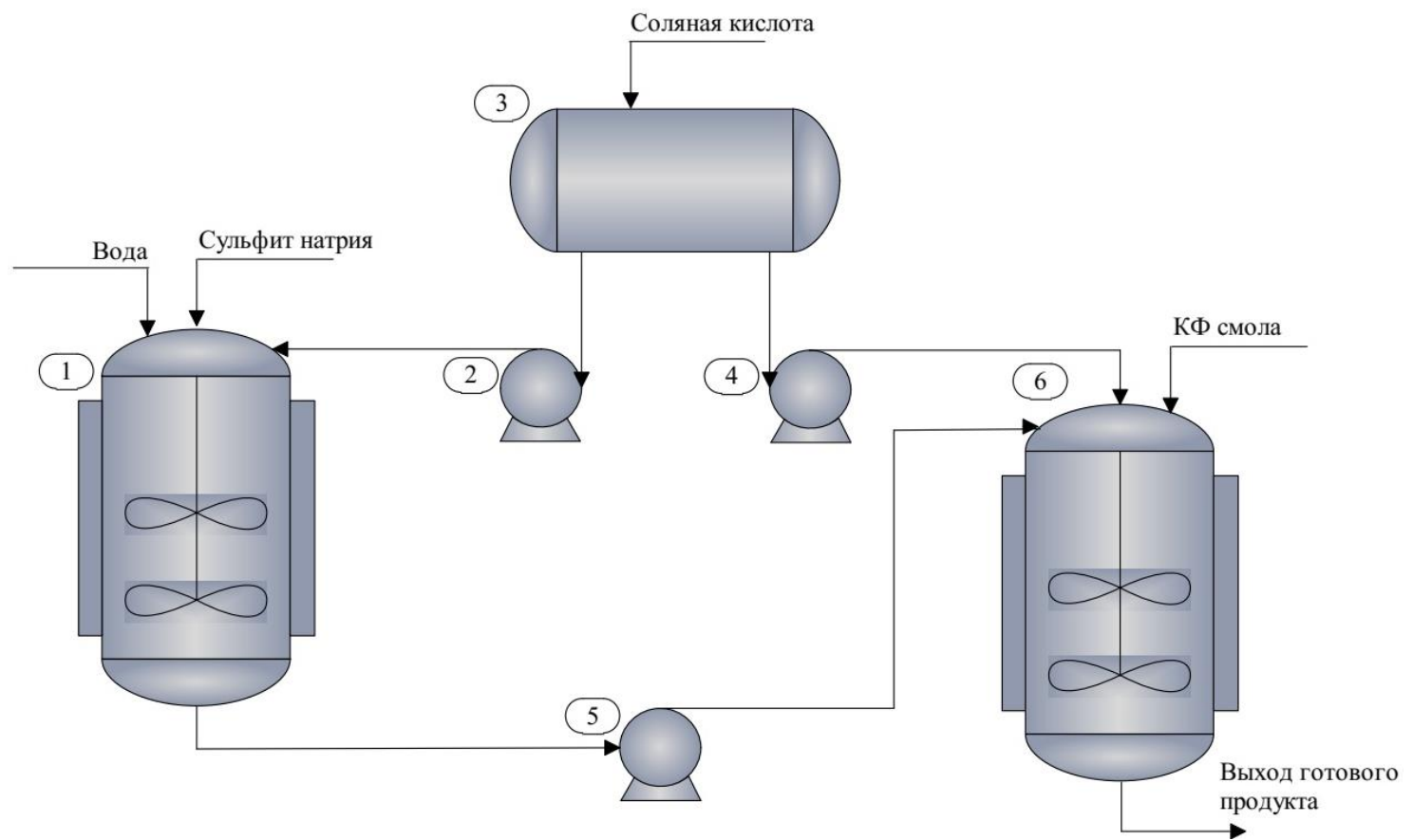

Рис. 2. Технологическая схема удаления формальдегида из КФ смол: 1 - аппарат для приготовления раствора гидросульфита натрия; 2, 4, 5-насос дозатор; 3 - бак-хранилище соляной кислоты; 6-реактор

Fig. 2. Technological scheme for formaldehyde removal from UF resins: 1 - apparatus for preparation of a solution of sodium hydrosulfite; 2, 4, 5 - pump dispenser; 3 -storage tank for hydrochloric acid; 6 -reactor

Подбор основного и вспомогательного оборудования производили на основании химических и физикохимических особенностей реагентов, технологических режимов и особенностей проведения процесса.

Реактор - 1 представляет собой аппарат с рубашкой, изготовленный из эмалированной стали, объем реактора - $1 \mathrm{~m}^{3}$, диаметр - 1 м, высота 1,45 м. В верхней части имеет 3 фланца для загрузки реагентов. Реактор снабжен электродвигателем для перемешивания реакционной массы. Перемешивающее устройство представляет собой якорную мешалку, соединенную жесткой муфтой с электродвигателем.
Насосы дозаторы - 2, 4, 5 выполнены из стали марки 12 Х18Н9ТЛ, производительностью 0,25, 0,2 и $1 \mathrm{M}^{3} /$ ч соответственно.

Бак для хранения соляной кислоты - 3 выполнен из легированной стали, объем - 0,5 м³, диаметр 0,85 м, высота - 0,9 м.

Реактор - 6 представляет собой аппарат с рубашкой, изготовленный из эмалированной стали, объемом 4 м $^{3}$, диаметром 2,4 м, высотой 3,02 м. В верхней части имеет 3 фланца для загрузки реактивов и муфту для соединения с электродвигателем мешалки.

Стоит отметить безотходность разработанной методики: продукт связывания формальдегида - метил- 
сульфат натрия - остается в КФ смоле и не ухудшает свойства. Твердых отходов и отходящих газов в ходе процесса не образуется.

\section{Методика эксперимента}

Удаление формальдегида из КФ смоль. В емкость для приготовления раствора гидросульфита натрия $\mathrm{NaHSO}_{3}$ заливается вода и сульфит натрия в количествах, необходимых для получения 25\%-го раствора. Из расходной емкости в емкость приготовления подается точное количество соляной кислоты, необходимое для протекания реакции, при этом ведется постоянное измерение $\mathrm{pH}$ при помощи рН-метра. Приготовленный раствор гидросульфита натрия при помощи крана-дозатора загружается в реактор приготовления экологически безопасной КФ смолы, куда заранее была загружена карбамидоформальдегидная смола и включен электродвигатель с мешалкой. Готовая модифицированная смола выгружается из реактора.

Определение свободного формальдегида в КФ смоле. 2 г КФ смолы растворяют в $55 \mathrm{~cm}^{3}$ дистиллированной воды и добавляют $5 \mathrm{~cm}^{3}$ раствора гидроокиси натрия или гидроокиси калия с массовой долей 30 \%. Определение свободного формальдегида проводят на $\mathrm{pH}$-метре - милливольтметре $\mathrm{pH}-340$ с платиновым и проточным хлорсеребряным электродами, при этом переключатель «размах» устанавливают в положение «1500 mV», а переключатель «род работы» - в положение «-mV». В стакан с раствором смолы или лака погружают электроды рН-метра и при перемешивании титруют раствором гидроксиламина гидрохлорида концентрации 0,1 моль/л $(0,1$ н.) до скачка потенциала (когда стрелка не вернется в крайнее левое положение). В конце титрования раствор гидроксиламина гидрохлорида приливают по каплям. Массовую долю свободного формальдегида в смоле или лаке $\mathrm{X}$ в процентах вычисляют по формуле: $\mathrm{X}=0,15 \mathrm{~V}$, где $\mathrm{V}$ - объем раствора гидроксиламина гидрохлорида концентрации 0,1 моль/л $(0,1$ н.), израсходованный на титрование $\mathrm{cm}^{3}$. За результат испытания принимают среднеарифметическое результатов двух параллельных определений.

Определение условной вязкости при $(20,0 \pm 0,5){ }^{\circ} \mathrm{C}$ по вискозиметру В3-246 с соплом диаметром 6 мм. Вискозиметр помещаем в штатив и с помощью уровня устанавливаем в горизонтальном положении. Под сопло вискозиметра ставим сосуд. Отверстие сопла закрываем пальцем, испытуемый материал наливаем в вискозиметр с избытком, чтобы образовался выпуклый мениск над верхним краем вискозиметра. Наполняем вискозиметр медленно, чтобы предотвратить образование пузырьков воздуха. Избыток материала и образовавшиеся пузырьки воздуха удаляем при помощи стеклянной пластинки или алюминиевого диска сдвигаемых по верхнему краю воронки в горизонтальном направлении таким образом, чтобы не образовалось воздушной прослойки. Открываем отверстие сопла и одновременно с появлением испытуемого материала из сопла включаем секундомер. В момент первого прерывания струи испытуемого материала секундомер останавливаем и отсчитываем время ис- течения. За результат испытания принимаем среднее арифметическое результатов не менее трех измерений времени истечения в секундах.

Определение времени желатинизащии при $100{ }^{\circ} \mathrm{C}$. В стакане взвешивают 50,0 г смолы. Смола должна иметь температуру $(20 \pm 1){ }^{\circ} \mathrm{C}$. Затем в стакан пипеткой добавляют 2,5 cм 3 водного раствора хлористого аммония концентрации $20 \%$ (1,0\% от массы смолы в пересчете на сухой хлористый аммоний) и после тщательного перемешивания палочкой в течение 5 мин получают клеевой раствор. В пробирке взвешивают около 2,00 г приготовленного клеевого раствора и опускают ее в кипящую водяную баню так, чтобы уровень клеевого раствора в пробирке был на 10-20 мм ниже уровня воды в водяной бане. Включают секундомер. Клеевой раствор непрерывно энергично перемешивают палочкой до начала его желатинизации. За время желатинизации принимают время в секундах с момента погружения пробирки в кипящую воду до момента потери текучести клеевого раствора. За результат испытания принимают среднее арифметическое результатов двух параллельных определений, допускаемое расхождение между которыми не должно превышать 2 с.

Определение смешиваемости КФ смоль с водой. В цилиндр наливают $50 \mathrm{~cm}^{3}$ смолы и, постепенно перемешивая, добавляют $100 \mathrm{~cm}^{3}$ дистиллированной воды температурой $(20 \pm 1){ }^{\circ} \mathrm{C}$. Смесь встряхивают, при этом в ней не должен образовываться хлопьевидный осадок, не должна происходить коагуляция смолы и в течение 5 мин не должно наблюдаться расслоение.

Определение предела прочности при скальввании по клеевому слою фанеры после вымачивания образцов в воде в течение 24 ч. В стеклянный или фарфоровый стакан помещают 500-600 г смолы, добавляют 5-6 г (1 \%) тонко измельченного хлористого аммония и тщательно перемешивают. В смолу добавляют древесную муку в количестве 1-3 \% от массы смолы.

Из шпона вырезают двенадцать листов размером не менее $240 \times 240$ мм и собирают четыре трехслойных пакета. Для этого на лист шпона, предназначенный для внутреннего слоя пакета, равномерным слоем

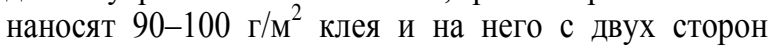
накладывают по одному листу сухого шпона при взаимно перпендикулярном расположении волокон. Из четырех трехслойных пакетов комплектуют общий пакет, помещают его в пресс, температура плит которого $125-130{ }^{\circ} \mathrm{C}$, и выдерживают под давлением $1,8 \ldots 2,0$ МПа (180-200 Н/ $\left.\mathrm{cm}^{2}\right)$ в течение 5,5 мин. Через 24 ч из каждого трехслойного пакета вырезают по шесть образцов и на 24 ч помещают для вымачивания в ванну с водой при $(20 \pm 2){ }^{\circ} \mathrm{C}$. После вымачивания образцы выкладывают на фильтровальную бумагу и через 10 минут испытывают.

Приспособление для испытания образцов укрепляют в захватах испытательной машины так, чтобы вертикальная ось приспособления совпадала с осями захватов машины. Образец устанавливают в приспособлении так, чтобы его лицевая сторона плотно прилегала к упорной планке приспособления с одинаковой силой прижима для каждого образца. Оси образца должны совпадать с осями приспособления. Изготовленные образцы закреп- 
ляют так, чтобы зажимные губки захватили их не далее чем на 5 мм от пропилов. Образец нагружают равномерно с постоянной скоростью нагружения или с постоянной скоростью перемещения нагружающей.

За результат испытания принимают наименьшее значение показателя при разрушении по клеевому слою. Результат испытания не учитывают, если разрушение произошло по древесине и показатель ниже нормы, предусмотренной настоящим стандартом.

\section{Заключение}

В результате лабораторных экспериментов была разработана лабораторная установка для удаления формальдегида из КФ смол и подобраны оптимальные условия проведения процесса: рекомендуемый интервал $\mathrm{pH}$ составляет $3,5 \ldots 4,0$, температуру реко-

\section{СПИСОК ЛИТЕРАТУРЫ/REFERENCES}

1. Roffael E., Behn C., Schneider T., Krug D. Bonding of recycled fibres with urea-formaldehyde resins. International Wood Products Journal, 2016, vol. 7, no. 1, pp. 36-45.

2. Osemeahon S.A., Barminas J.T., Aliyu B.A., Maina H.M Development of amino resins for emulsion paint formulation effect of aldelhydic group and degree of substitution. African Journal of. Biotechnology, 2007, vol. 6, no. 22, pp. 2532-2540.

3. Tsubota T., Takenaka K., Murakami N., Ohno T. Performance of nitrogen- and sulfurcontaining carbon material derived from thiourea and formaldehyde as electrochemical capacitor. Journal of Power Sources, 2011, vol. 196, no. 23, pp. 10455-10460.

4. Sun G., Ma L., Ran J., Li B., Shen X., Tong H. Templated synthesis and activation of highly nitrogen-doped worm-like carbon composites based on melamine-urea-formaldehyde resins for high performance supercapacitors. Electrochimica Acta, 2016, vol. 194, pp. 168-178

5. Ibrahim D.M., Abu-Ayana Y.M. Preparation of nano alumina via resin synthesis. Materials Chemistry and Physics, 2009, vol. 113 no. 2-3, pp. 579-586.

6. Senkal B.F., Yavuz E. Ureasulfonamide polymeric sorbent for selective mercury extraction. Monatshefte für Chemie, 2006, vol. 137, no. 7, pp. 929-934.

7. Nektarios P.A., Nikolopoulou A.-E., Chronopoulos I. Sod establishment and turfgrass growth as affected by ureaformaldehyde resin foam soil amendment. Scientia Horticulturae, 2004, vol. 100, no. 1-4, pp. 203-213.

8. Zhang D.-X., Li B.-X., Zhang X.-P., Zhang Z.-Q., Wang W.-C., Liu F. Phoxim microcapsules prepared with polyurea and ureaformaldehyde resins differ in photostability and insecticidal activity. Journal of Agricultural and Food Chemistry, 2016, vol. 64 , no. 14 , pp. $2841-2846$.

9. Ghani A., Ashaari Z., Bawon P., Lee S.H. Reducing formaldehyde emission of urea formaldehyde-bonded particleboard by addition of amines as formaldehyde scavenger. Building and Environment, 2018, vol. 142, pp. 188-194.

10. Wang S.M., Shi J.Y. Study on curing characteristics of lowtoxicity urea-formaldehyde resin. Advanced Materials Research, 2011, vol. 393-395, pp. 1447-1450.

11. Pang J.Y., Sun C., Zhang S.C., Cui H.X. Study on modification of urea formaldehyde resin with keratin. Advanced Materials Research, 2010, vol. 113-116, pp. 1787-1791. мендуется поддерживать в интервале $20-40{ }^{\circ} \mathrm{C}$, количество гидросульфита натрия должно составлять $1,5 \ldots 1,75$ от стехиометрического соотношения, процесс рекомендуется проводить при атмосферном давлении. На основании лабораторных экспериментов разработан способ удаления свободного формальдегида из КФ смолы, составлена технологическая схема процесса и подобрано необходимое оборудование. Разработанная технологическая схема позволяет получить КФ смолу с низким содержанием формальдегида без ухудшения эксплуатационных свойств. В разработанной технологии не применяются катализаторы и дорогостоящие реагенты, отсутствуют отходы, а процесс проводится на доступном технологическом оборудовании.

12. Dazmiri M.K., Kiamahalleh M.VOL., Dorieh A., Pizzi A. Effect of the initial $\mathrm{F} / \mathrm{U}$ molar ratio in urea-formaldehyde resins synthesis and its influence on the performance of medium density fiberboard bonded with them. International Journal of Adhesion and Adhesives, 2019, vol. 95, pp. 102440

13. Akinyemi B.A., Olamide O., Oluwasogo D. Formaldehyde free particleboards from wood chip wastes using glutaraldehyde modified cassava starch as binder. Case Studies in Construction Materials, 2019, vol. 11, p. e00236.

14. Yu Y., Xu P., Chen C., Chang J., Li L. Formaldehyde emission behavior of plywood with phenol-formaldehyde resin modified by bio-oil under radiant floor heating condition. Building and Environment, 2018, vol. 144, pp. 565-572.

15. Cheng Y., Tian Q.K., Li R. The Utilization of Phenol Components in Bio-Oil for Modifying Urea-Formaldehyde Resin Adhesive. Advanced Materials Research, 2015, vol. 1096, pp. 209-213.

16. Valarelli I.D., Batistelle R.A.G., Branco L.A.M.N., Chahud E., Christoforo A.L., Rocco Lahr F.A., Bezerra B.S. Evaluation of bamboo particleboards produced with urea-formaldheyde resin. Advanced Materials Research, 2014, vol. 1025-1026, pp. 432-435.

17. Chen G.H., Han J., Zhang X.H. Study on synthetic process of low toxic urea-formaldehyde resin. Advanced Materials Research, 2012, vol. 621, pp. 79-82.

18. Despres A., Pizzi A., Vu C., Delmotte L. Colourless formaldehyde-free urea resin adhesives for wood panels. European Journal of Wood and Wood Products, 2010, vol. 68, pp. 13-20.

19. Wen M., Zhu L., Zhang Y., Tan H., Gu J. Activator of ureaformaldehyde resin adhesive with expediting setting and lowformaldehyde-emission. Linye Kexue/Scientia Silvae Sinicae, 2016, vol. 52, pp. 99-105.

20. Pereira F., Pereira J., Paiva N., Ferra J., Martins J.M., Magalhães F.D., Carvalho L. Natural Additive for Reducing Formaldehyde Emissions in Urea-Formaldehyde Resins. Journal of Renewable Materials, 2016, vol. 4, no. 1, pp. 41-46.

21. Wang B., Zhang Y., Tan H., Gu J. Melamine-urea-formaldehyde resins with low formaldehyde emission and resistance to boiling water. Pigment \& Resin Technology, 2019, vol. 48, pp. 229-236.

22. Gangi M., Tabarsa T., Sepahvand S., Asghari J. Reduction of formaldehyde emission from plywood. Journal of Adhesion Science and Technology, 2013, vol. 27, pp. 1407-1417.

Поступила: 03.11.2021 2.

\section{Информация об авторах}

Липин К.В., кандидат химических наук, доцент кафедры химической технологии и защиты окружающей среды Чувашского государственного университета имени И.Н. Ульянова.

Федосеев $\boldsymbol{C}$.B., кандидат химических наук, доцент кафедры органической и фармацевтической химии Чувашского государственного университета имени И.Н. Ульянова.

Кизяев Д.А., главный технолог ПАО «Химпром». 
UDC 665.939 .56

\title{
TECHNOLOGY FOR REMOVING FREE FORMALDEHYDE FROM UREA-FORMALDEHYDE RESINS
}

\author{
Konstantin V. Lipin'1, \\ lipinkost@mail.ru
}

\section{Sergey V. Fedoseev 1 , sergey.fedoseev88@gmail.com}

\author{
Denis A. Kizyaev², \\ denis.kizyaev@yandex.ru \\ 1 Chuvash State University, \\ 15, Moskovskiy avenue, Cheboksary, 428015, Russia. \\ 2 PJSC «Khimprom», \\ 101, Promyshlennaya street, Novocheboksarsk, 429965, Russia.
}

The relevance of the study is caused by high danger of technogenic emission of formaldehyde into the environment. The main anthropogenic source of formaldehyde is the production of particle board, which uses urea-formaldehyde resins. The paper proposes a technology for removing free formaldehyde from urea-formaldehyde resins, which will increase the safety and environmental friendliness of products based on them. The results of the work will make it possible to safely utilize and make the most optimal use of the available georesources, thereby solving one of the main tasks of geoecology.

The aim of this work is to develop a method for reducing the toxicity of urea-formaldehyde resins by removing free formaldehyde.

Objects: urea-formaldehyde resins characterized by the possibility of formaldehyde emission.

Methods: modeling of the optimal process parameters; laboratory methods for formaldehyde removal; laboratory methods for studying the physical and mechanical properties of the modified urea-formaldehyde resin; modeling the required equipment and technological scheme. Results. The authors have developed the laboratory installation to remove formaldehyde from urea-formaldehyde resins and selected the optimal conditions for the process: the recommended $\mathrm{pH}$ range is $3,5 \ldots 4,0$, the temperature is recommended to be maintained in the range of $20-40{ }^{\circ} \mathrm{C}$, the amount of sodium hydrosulfite should be 1,5...1,75 of the stoichiometric ratio, the process is recommended to be carried out at atmospheric pressure. On the basis of a laboratory setup, a technological scheme for production of environmentally friendly urea-formaldehyde resins, consisting of two stages: the preparation of the sodium hydrosulfite reagent and its interaction with ureaformaldehyde resin, was developed. The necessary main and auxiliary equipment was selected for the technological scheme. The process requires two jacketed reactors with a stirrer, three dosing pumps and a hydrochloric acid storage tank. Within the framework of this study, the investigation of the physical and mechanical properties of the modified urea-formaldehyde resin was carried out. The results obtained deviate somewhat from the results of the study of the original urea-formaldehyde resin, but are within the permissible limits.

\section{Key words:}

Formaldehyde, urea-formaldehyde resins, formaldehyde emission, formaldehyde removal, modification of urea-formaldehyde resin.

\section{Information about the authors}

Konstantin V. Lipin, Cand Sc., associate professor, Chuvash State University. Sergey V. Fedoseev, Cand Sc., associate professor, Chuvash State University.

Denis A. Kizyaev, chief engineer, PJSC «Khimprom». 